\title{
O PESSOAL E O POLÍTICO: O MUNDO NA CASA
}

\author{
Adriana Albano \\ (Universidade Estadual de Roraima)
}

\section{RESUMO}

Este trabalho pretende estudar a complexa construção da identidade no livro Um rio chamado tempo, uma casa chamada terra de Mia Couto. Observaremos como esta escrita negocia conceitos da tradição e da contemporaneidade em estreita relação com a noção de entre-lugar de Homi Bhabha (2001) no livro O local da cultura e com a ideia de indecidível de Jacques Derrida.

PALAVRAS-CHAVE: identidade, entre-lugar, indecidível.

\begin{abstract}
This work intends to study the complex construction of the identity from the book Um rio chamado tempo, uma casa chamada terra of Mia Couto. We will observe how this writing negotiates concepts of tradition and contemporaneity in close relation with the notion of in-between from Homi Bhabha (2001) in the book The location of culture and with the idea of undecidable of Jacques Derrida.
\end{abstract}

KEYWORDS: identity, in-between, undecidable. 
Quando Elegbara engoliu e restituiu tudo, mostrou que é a boca que organiza o mundo, através da fala. É a palavra proferida que recria o mundo, percebido e devolvido com significado próprio.

Monique Augras

\section{INTRODUÇÃO}

Em Um rio chamado tempo, uma casa chamada terra de Mia Couto (2003), percebemos as articulações da narrativa na tentativa de construção do cenário moçambicano pós-colonial. Nesse movimento, instala-se como entre-lugar a identidade, principalmente, do personagem Marianinho, dividido entre o passado e o presente quando revisita a ilha natal, Luar do Chão. Divisão que não se apresenta de forma binária, pois, na recriação espaço-temporal da história familiar, sua identidade submerge desconstruindo a noção de passado colonial e de presente pós-colonial. Ocorre que o universo das raízes familiares contamina profundamente o tempo presente, num vai e vem intenso até o momento de se confundirem, transformando passado e presente. Nesse fluxo, também outras identidades, inseparáveis do tempo contaminado, se tornam deslizantes.

O objetivo desse estudo é pensar as complexas formações da identidade cultural da nação moçambicana pós-colonial por meio da narrativa literária de Mia Couto acima mencionada. Importa, aqui, menos criticar o texto do que elucidar o mecanismo de funcionamento da construção da subjetividade por meio da narrativa ficcional, do entre-lugar, do indecidível que esta coloca.

A ideia de entre-lugar é oriunda dos estudos que Homi Bhabha (2001) desenvolve em O local da cultura. Na obra, o autor indo-britânico defende que as diferenças culturais devem ser pensadas por meio desse espaço deslizante, uma vez que o lugar "nem aqui nem lá" permite pensar "além das narrativas de subjetividades originárias e iniciais" (BHABHA, 2001, p. 20). Entendemos o movimento do entre-lugar como o do fort:da de Freud (1920) em "Além do Princípio de Prazer", em que o médico analisa e interpreta o jogo de envio e retorno de um carretel por uma criança. ${ }^{1}$ movimento de ir, revir que oscila entre um e outro para que a relação seja possível e para que a ligação não seja rompida. É presente o desejo de reinvindicação do passado (não um passado historicista de cunho monumental), mas um passado-no-presente que desconstrói a noção de estereótipo da nação para dar lugar à articulação de temporalidades subjetivas que aproximam-se insistentemente para distanciarem-se novamente, expondo, nesse jogo de afastamento e aproximação, a relação desaparecimento/reaparecimento do objeto, que se estende ao sujeito: o desaparecimento de um corresponde ao desaparecimento do outro. 
Nesse movimento de proximidade e distância, de articulação e desarticulação, de deslocamento, se compõem as identidades, desconstruindo visões essencialistas de classe, raça e gênero que sempre estão associadas à ideia de formaçao de um povo. Segundo Bhabha (2001), é a partir desse modo de pensar que poderá surgir um projeto de comunidade que leve em conta as causas multiculturalistas, já que estas apresentam as subjetividades entrecruzadas no espaço da comunidade. $\mathrm{O}$ crítico indo-britânico, a partir de tais considerações, questiona:

De que modo chegam a ser formuladas estratégias de representação ou aquisição de poder [empowerment] no interior das pretensões concorrentes de comunidades em que, apesar de histórias comuns de privação e discriminação, o intercâmbio de valores, significados e prioridades pode nem sempre ser colaborativo e dialógico, podendo ser profundamente antagônico, conflituoso e até incomensurável? (BHABHA, 2001, p. 20)

A partir da intervenção de temporalidades presente na construção da narrativa de Mia Couto (2003) - a articulação do passado com o presente rearticula também as identidades dos personagens -, propomos um olhar sobre o constante deslocamento das relações sociais/familiares como modo de redescrever o ir e vir que constitui a construção da comunidade. O movimento indecidível temporal possibilita que as identidades não sejam representadas de modo já autenticado e fixo. O que ocorre na tentativa de não hierarquizar a diferença, mas sim reproduzi-la, descentralizá-la, re-marcando as margens e produzindo a identidade-em-diferença como condição de existência da comunidade moderna (DERRIDA, 1991, p. 107).

É questão complexa a da diferença cultural como condição de construção de comunidade na medida em que tal deslocamento corresponde também ao deslocamento de verdades históricas e filosóficas: diferença que compõe a significância das sociedades humanas.

\section{SOMBRAS}

O acontecimento do texto de Mia Couto manifesta-se na condição crepuscular, entre a escuridão e o nascer do sol: no cenário da globalização, do neoliberalismo, mas também da memória e da história, da tradição e das raízes. O projeto de escrita de alguma subjetividade está indiscutivelmente ligado ao período da pós-colonização, e às alianças político-econômicas que se estabelecem por meio da representação das relações sociais, mas também à irrupção de acontecimentos de um passado/presente sombrio. São expostos os traumas e os silêncios que se perpetuam nas entranhas da tradição familiar, local, rural: estupro, adultério, assassinato e corrupção política. Desse modo, tal construção literária não pode ser considerada fora do processo de tentativa de afirmação e reconhecimento da identidade própria, mas ainda num trabalho de descolonização e de constante remanejamento dos valores. 
O indecidível que acompanha a ideia de entre-lugar consiste na presença/ausência de centro organizador no processo de reconhecimento, é um ato de articular as existências presente, passada e futura. O conceito é oriundo dos estudos de Jacques Derrida (1995), principalmente, em Salvo o nome: um processo infinito de constituição do sujeito que perpassa todos os tempos em uma estrutura em constante remanejamento, numa tentativa fantasmática, ilusória de conciliação das partes, consistindo em deslocar-se rumo ao desconhecido, rumo ao impossível, como afirma Derrida: "Ir aonde é possível ir não seria um deslocamento ou uma decisão; seria o desenvolvimento irresponsável de um programa. A única decisão possível passa pela loucura do indecidível e do impossível: ir aonde (wo, Ort, Wort) é impossível ir" (DERRIDA, 1995, p. 42). Pois nada em tal processo pode ser controlado.

Na trilha da história moçambicana, esperava-se que, após a descolonização, a identidade nacional se reestruturaria, assim como emergiriam suas dimensões culturais, (ROSÁRIO, 2010). Teoricamente, a nação se equilibraria entre a recusa aos valores do colonizador e a afirmação das verdadeiras raízes, daí "sairia o novo africano, pronto a gerir o que de melhor herdou da sua convivência com o dominador e o melhor que pode resgatar das suas raízes" (ROSÁRIO, 2010, p. 79). Todavia, o cenário mostra-se complexo, multicultural, confundindo a visão que procura formações autônomas, blocos homogêneos e estereotípicos.

Ao longo do livro, percebemos que a subjetividade construída pela linguagem na narrativa ficcional propõe os contornos da identidade múltipla, multilíngue, multiétnica: indecidível. Contornos que antes de apresentarem um sentido definido, definitivo, profundo, chamam à percepção a ausência de centro organizador em uma (des)estrutura de relações de força em constante reformulação. O todo do romance está aberto aos acontecimentos, uma vez que é apresentado em pedaços, em histórias pessoais que estão à deriva, mas ao mesmo tempo, "prometem" uma reorganização em outro lugar, a posteriori.

Tal ficcionalidade garante ao discurso a autonomia de abrir-se a uma infinidade de possibilidades, tornar-se indômito. Nesse tecido literário, percebemos o espaço em que são construídos significados que, antes de proporem verdades, descamam-nas ao mesmo tempo em que, à roda das lendas, dos delírios do personagem, des-cobrem o corpo instável e dinâmico da articulação da identidade sempre se re-fazendo. Não há sujeito constituído, nem objeto, mas tecido vivo além da essencialização proposta pelo olhar do Ocidente. Como afirma Mia Couto, "Há tantas Áfricas quanto escritores, e todos eles estão reinventando continentes dentro de si mesmos." (COUTO, 2011, p. 22).

Uma das principais estratégias da narrativa para apresentar a fragmentação das identidades consiste na introdução do gênero carta que surge no romance e contamina a narrativa na medida em que provoca $\mathrm{o}$ rearranjo das relações familiares e da própria história. 
As cartas do avô Dito Mariano aparecem misteriosamente para revelar ao jovem Marianinho histórias familiares que determinam as relações que o personagem passa a desenvolver com a família. O tempo passado longe da terra natal distancia este das tradições locais e familiares. As revelações evidenciam características culturais do viver daquela família, como a personalidade do avô e seu modo de se relacionar com as mulheres da família, o modo frio como o pai o tratava, a ambição do Tio Ultímio...

A fala do avô, por meio das cartas, é carregada de afetividade e arrependimento, desconstruindo a imagem de distanciamento que o neto e a avó formaram: alguém que não demonstrava carinho ou preocupação com a família. Por meio das cartas também é revelado a Marianinho quem são seus pais verdadeiros, acontecimento que promove mudança no modo de ver e experimentar o mundo local, na medida em que aumenta sua responsabilidade na preservação dos laços e da tradição de seu grupo familiar. A emergência desta nova verdade: o avô é seu pai, procura, no romance de Couto aqui analisado, "reordenar as contingências passadas dando-lhes o sentido das necessidades por vir” (DERRIDA, 2007, p. 520).

No capítulo "O carteiro da verdade", do livro O cartão-postal: de Sócrates a Freud e além, Derrida (2007) faz uma leitura do Seminário de Lacan sobre "A carta roubada" (1998). No conto de Edgar Allan Poe, a presença da carta determina o lugar dos personagens e suas ações na narrativa. Em articulação semelhante, as cartas do avô rearticulam as identidades, principalmente a do personagem principal, Marianinho. O conteúdo da carta de Poe não é revelado, porque o que importa é sua relação com o mundo exterior ao da carta. Nas cartas de Dito Mariano, que desaparecem ao serem lidas, ocorre que a metamorfose provocada no neto e nas relações sociais vivenciadas por este importa como objetivo, e não o escrito em si, este não se transforma em registro, é apagado logo depois da leitura e passa a fazer sentido de outra forma: na comunidade de Luar do Chão, como veremos a seguir.

\section{O PÚBLICO E O PARTICULAR}

O personagem principal, Marianinho, retorna à terra natal, Luar do Chão, para o enterro do avô Dito Mariano, que, segundo o médico indiano Amílcar Mascarenha, ainda não está completamente morto. Os acontecimentos se inserem no espaço do fantástico e do mistério, uma vez que o quase-morto envia cartas reveladoras ao neto Marianinho durante a estada deste na ilha para o enterro.

As cartas do avô instauram outra narrativa dentro do livro. Propõem a outridade do sujeito: surgem para Marianinho em situações imprevisíveis e somente as últimas vêm com a assinatura do avô Mariano, revelando o "remetente". Cartas de um morto, mas enviadas no presente. Todavia, quando o estudante começa a refletir sobre essa escrita, percebe que a letra é muito parecida com a sua e que só ele e a avó podem enxergá- 
-las. Outro acontecimento que torna o aparecimento inusitado é o fato de que sempre são destruídas, de algum modo, logo após a leitura, sinalizando a efemeridade das revelações (movimento de rastro): movimento de fort-da: não objetivam o registro ou arquivo, mas sim movimento de transformação e de salvamento de si e da família, da casa, da terra. Movimento de jogo em que "Ele perde em todos os lances e ele ganha em todos os lances, na medida em que ele está ali antes de estar ali, desde que ele se prepare para sua presença, onde ele ainda está quando se reserva para se produzir, invadindo tudo aém dele mesmo" (DERRIDA, 2007, p. 447). Materialidade e evanescência se articulam e apresentam a tensão interna/externa recorrente, como se as cartas fossem inventadas (inventar: etimologicamente encontrar o que já está lá) pelo próprio destinatário como modo de dar a conhecer a si e ao leitor as outras histórias que compõem todas as histórias pessoais, e ao mesmo tempo do clã moçambicano encenado no romance.

As cartas propõem "subjetividades" em transição, que se rearranjam à medida que os acontecimentos vêm à tona por meio das revelações que se dão durante a estada do estudante "Marianinho",

Essas cartas, Mariano, não são escritos. São falas. Sente-se, se deixe em bastante sossego e escute, você não veio a essa Ilha para comparecer perante um funeral. Muito ao contrário, Mariano. Você cruzou essas águas por motivo de um nascimento. Para colocar o nosso mundo no devido lugar. Não veio salvar o morto. Veio salvar a vida, a nossa vida. Todos aqui estão morrendo não por doença, mas por desmérito do viver. [...] E salvarmos nossa família, que é o lugar onde somos eternos. (COUTO, 2003, p. 64-65)

Coloca-se em cena o sujeito moçambicano pós-colonização na redescoberta de si, de seu lugar dentro do contexto familiar, social. A ideia de salvamento, posta de modo tão patente, abrindo a primeira carta recebida, propõe o projeto de escrita, propõe a tentativa precária de restituição daquilo que está presente por meio do retorno a um tempo ausente, mítico, num movimento que carrega o rastro arcaico no momento de busca do "passado" (em passado como presença) na escrita da vida. Podemos ler como um gesto "imunitário (e, pois um movimento de salvação, de salvamento e de salvação do salvo)" (DERRIDA, 2002a, p. 87) de salvar o que vai além de si e do texto, a incomensurabilidade da existência.

Entretanto, o discurso narrativo acaba funcionando como o centro de polaridades em tensão: a afirmação da identidade revela o desejo de se manter diverso devido às injustiças que essa história comporta, todavia, existe a necessidade de aproximação e identificação, porque tudo aquilo que rejeita é parte de si mesmo. A "dialética" identidade/diferença é expressa no livro por meio das estratégias retóricas que oscilam entre a linguagem da "realidade" do momento sócio-histórico e o das histórias pessoais, a descrição do ambiente interno (casa) e externo (entorno), o individual e o coletivo: 
O médico então lhe contou toda a história: aquela moça era Mariavilhosa. [...] Há uns meses a desgraçada tinha vindo ao seu encontro: fora violada e engravidara. Para abortar, no segredo, Mariavilhosa fizera uso da raiz da palmeira Lala. Espetara-a no útero, tão fundo quanto fora capaz. Mascarenha encontrara-a num estado deplorável: as entranhas infectadas, sangue apodrecendo no ventre. [...] Mas a moça deveria prosseguir um tratamento continuado que só poderia ser administrado na capital. Ora, naquele tempo, os negros estavam proibidos de viajar no barco. O Vasco da Gama era só para os brancos. (COUTO, 2003, p. 104)

O trecho acima é o relato do médico da família sobre a suposta mãe de Marianinho. Ela fingira-se de marinheiro para viajar e poder realizar o tratamento pós-aborto e, nessas viagens, conhecera Fulano Malta, suposto pai do protagonista. Mas Mariavilhosa, tempos após ter se casado com Fulano, entrou no rio e nunca mais voltou:

- É verdade que minha mãe morreu afogada?

Afogada era um modo de dizer. Ela suicidara-se, então? A avó escolhe cuidadosamente as palavras. Não seria suicídio também. O que ela fez, uma certa tarde, foi desatar a entrar pelo rio até desaparecer, engolida pela corrente. Morrera? Duvidava-se. Talvez se tivesse transformado nesses espíritos da água que, anos depois, reaparecem com poderes sobre os viventes. (COUTO, 2003, p. 105)

Percebemos, nessas passagens, que o histórico da colonização (proibição dos negros viajarem nos barcos, estupro das mulheres pelos portugueses) se mistura à vida íntima das crenças e da tradição moçambicana. O passado ocultado é revelado e o privado e o público contaminam-se forçando uma visão ex-cêntrica.

Por meio das cartas, é revelado a "Marianinho" que este é filho do avô com a irmã mais nova da mãe, Tia Admirança,

Mas com o tempo o menino cresceu, foi ganhando feições. Admirança definhava só em pensar que esse moço ia revelando a identidade do pai verdadeiro. Ela me suplicou que deixasse esse filho sair da ilha. Ele que crescesse fora, longe das vistas. E longe de sua culpa. E o menino foi mandado para a cidade. Lá se fez homem, um homem acertado no sentimento. Esse homem é você, Mariano. Admirança é sua mãe. (COUTO, 2003, p. 235)

Revelação que na trama aproxima ainda mais o jovem da responsabilidade de cuidar da herança deixada por Dito Mariano: a casa Nymumba-caya e tudo o que ela re-apresenta. Herança que provoca constante conflito entre o antigo e o novo, entre um conjunto de representações antagônicas que problematiza a construção imaginária de um presente pós-colonial. 
Como estratégia de escrita, as cartas propõem ainda intertextos cujos efeitos expressam simbolicamente o tempo de redescoberta e as articulações dinâmicas a que está sujeita a afirmação da identidade cultural moçambicana. Estabelecem a contaminação do mundo social pelas crenças da tradição moçambicana, do mito pela realidade social. O olhar do personagem proveniente da cidade precisa ser remodelado a partir do contato com a tradição familiar da qual se distanciou quando foi estudar longe da terra natal. "Marianinho" é o estranho no ninho, é aquele que precisa se reencontrar para fazer parte do universo de Luar-do-Chão e salvá-lo da degradação, da pobreza e da corrupção.

A ficção narrativa é atravessada pelo discurso das cartas misteriosas, revelando segredos do núcleo familiar que não passam pela essencialidade da tensão entre bem e mal, como poderia ocorrer sob o olhar ocidental que enxerga opostos excludentes (NIETZSCHE, 2005). O discurso revelador suspende o véu que oculta a presença do outro intersubjetivo, obrigando o personagem principal, "Marianinho", à experienciação - experiência como processo - constante que se dá por meio da linguagem, da escrita das cartas que irrompem nos cômodos da casa e o re-colocam numa cadeia em movimento.

O reencontro é o mote do romance, a casa Nyumba-caya simboliza o espaço das raízes que no presente é um "negócio" para o ambicioso Tio Ulímio. Ele deseja vendê-la para lá construir um hotel e um cassino, ícones do neoliberalismo econômico que no romance representa o fim do que poderia conferir o retorno, a re-visita, a interação entre a tradição e o projeto de futuro: "Confessa, então, o fio de sua ambição. Ele quer desfazer-se da casa da família. E vender Nyumba-Kaya a investidores estrangeiros. Ali se faria um hotel." (COUTO, 2003, p. 151). A importância da articulação entre o passado tradicional e a necessidade de desenvolvimento se dá porque, como afirma Fanon (1986 apud BHABHA, 2001, p. 29 ), é importante que povos que passaram por um período de colonização afirmem a própria tradição cultural nativa e resgatem suas narrativas reprimidas, todavia não se pode esquecer do perigo da tentativa de fixidez de identidades atreladas ao romance celebratório das raízes ou da tentativa de se apresentar um presente único e universal que busque o crescimento a qualquer custo. Assim, (des)construir uma identidade a partir do espaço do entre-lugar passa pela negociação entre um projeto de passado e um de futuro que esteja aberto ao indecidível.

Ao mesmo tempo, apresentam-se outros familiares que compõem o cenário familiar: o suposto pai Fulano Malta, homem de frios e contidos gestos, amargurado pela precoce morte da esposa e pela situação do país,

Vasco da Gama. Fazia ligação com a cidade e, como sempre, ia sobrecarregado de gente e mercadoria. A ambição dos novos proprietários, todos reconheciam a meia voz, estava na origem do acidente. Sabia-se o nome dos culpados mas, ao contrário das letras verdes no casco, a identidade dessa gente 
permaneceria oculta. [...] Quando o barco foi engolido pelas águas, o céu da Ilha se transtornou. Um golpe roubou a luz e as nuvens se adensaram. (COUTO, 2003, p. 99)

Fulano Malta é um ex-guerrilheiro que lutou pela libertação do país e encontra-se frustrado pelas condições de miséria em que este se encontra depois da independência. Vê os antigos ideais de liberdade e desenvolvimento para o povo moçambicano traídos pelo jogo de interesses econômicos e políticos que se instalou depois da guerra. Também chora a morte da esposa Mariavilhosa e a ausência do filho que se mudara para a cidade, vive no passado de Luar-do-chão. Revolta-o o irmão Ultímio, a ambição, a soberba, o desinteresse pela melhoria de vida do povo da cidade e as alianças ambíguas que ele estabelece em proveito próprio. Os elementos que alimentam os embates entre os dois irmãos (as discussões sobre a venda da casa, a pressa em enterrar o pai para que esse passado e a tradição sejam também "enterrados" dando lugar à modernidade, o preconceito em relação ao médico indiano, grupo étnico com o qual realiza alianças comerciais, o uso de um carro luxuoso em local de miséria e fome) sobrepõem as vozes de dois discursos sociais antagônicos que formam o plano semântico de exposição de um dado momento histórico.

Por meio do conteúdo das cartas, constrói-se a identidade cuja temporalidade é mítica, não opositiva, espaçada. A inserção desse gênero suplementa ${ }^{2}$ o campo de forças em que atuam as identidades de todos os personagens. Estas só significam a partir da diferença que estabelecem umas com as outras, sempre na perspectiva do outro. As missivas são o contato performático do personagem com a coletividade, do particular com o público, é um lugar de suplementaridade, de releitura de um ser e de um tempo, criando a ilusão da origem e colocando as diferenças. O "um-no-outro", proporcionado pelo olhar que se volta e repensa uma história, expõe as complexas relações sociais. Contradição entre campo e cidade, contradição cultural e religiosa... redescoberta de raízes em busca do nascimento em estado de embrião.

\section{CONSIDERAÇÕES FINAIS}

O romance expõe as várias faces da multiculturalidade na nação moçambicana. Aqui, real e ficção não se excluem, mas se complementam para a significação da nação. A ficção se apropria de elementos da "realidade" histórica (o barco que afunda matando dezenas de pessoas por excesso de peso e carga, a entrada do tráfico de drogas na vila, o trabalho deformador na fábrica de caju, a impunidade, a miséria), incorpora-os sem hierarquizá-los, produzindo um rearranjo que desconstrói a familiaridade com as quais são concebidas a priori. Essas articulações literárias são expressas pelo embate entre as vozes sociais, pelos acontecimentos místicos, pela caracterização dos personagens e pelo enredo que gira em torno do retorno do jovem - aquele a quem as revelações de um passado surgem a 
todo momento, desconstruindo a percepção que tem de si e da sua família, pois parece que tudo começa a existir para si a partir dos encontros e das revelações surgidas em Luar-do-Chão - para a conclusão de um funeral carregado de mistério e revelação.

Desse modo, o estilo ficcional, segundo Iser (1978), não ilustra uma verdade totalizadora, mas a diversidade do olhar sobre si dentro do espaço político e cultural, no caso, o do jovem Marianinho, sujeito moçambicano. Cria uma tensão na narrativa, o conflito suspenso sem promessa de cessar, mas que se estabelece como continuum.

O estudo das diferenças que existem dentro da cultura por meio da narrativa literária nos apresenta a formação de um saber social que carrega em si contradições que precisam ser negociadas ao invés de negadas. Tal estudo é capaz de rearticular as noções de identidade a partir da significação dos povos marginais, aqueles que passaram por processos de colonização e as mulheres. Esses grupos resistem a processos de homogeneização. Por meio da diferença cultural e do espaço do entre-lugar, é possível desarticular os discursos de poder e saber, estabelecendo novos campos para a significação. O processo de significação obedece ao movimento de deslocamento, substituição e projeção, pois é definido a partir do outro (BHABHA, 2001, p. 288). Talvez o reconhecimento da diferença dentro do espaço da comunidade possa favorecer um movimento de solidariedade política.

\section{REFERÊNCIAS BIBLIOGRÁFICAS}

BHABHA, Homi K. O Local da Cultura. Trad. Myriam Ávila, Eliana de Lourenço de Lima Reis, Gláucia Renate Gonçalves. Belo Horizonte: UFMG, 2001.

COUTO, Mia. Um rio chamado tempo, uma casa chamada terra. São Paulo: Companhia das Letras, 2003.

COUTO, Mia. E se Obama fosse africano? São Paulo: Companhia das Letras, 2011.

DERRIDA, Jacques. O animal que logo sou. Trad. Fábio Landa. São Paulo: UNESP, 2002a.

. O cartão-postal: de Sócrates a Freud e além. Trad. Ana Valéria Lessa, Simone Perelson. Rio de Janeiro: Civilização Brasileira, 2007.

. A escritura e a diferença. 3. ed. Trad. Maria Beatriz M. N. da Silva. São Paulo: Perspectiva, 2002b. Papirus, 1991.

. Limited Inc. Trad. Constança Marcondes Cesar. Campinas: . Salvo o nome. Trad. Nícia Adan Bonatti. São Paulo: Papirus, 1995. 
FREUD, Sigmund. Além do princípio de prazer. In: Edição standard brasileira das Obras psicológicas completas de Sigmund Freud, v. 18. Rio de Janeiro: Imago, 1920.

ISER, Wolfgang. The Act of Reading: a theory of äesthetic response. Routledge, Kegan Paul. London and Henley, 1978.

LACAN, Jacques. Escritos. Trad. Vera Ribeiro. Rio de Janeiro, Jorge Zahar, 1998.

NIETZSCHE, Friedrich. Para além do bem e do mal: prelúdio a uma filosofia do futuro. Trad. Alex Marins. São Paulo: Martin Claret, 2005.

ROSÁRIO, Lourenço. Moçambique: história, culturas, sociedade e literatura. Belo Horizonte: Nandyala, 2010.

\section{Recebido para publicação em 30/11/14}

Aprovado em 22/01/15

\section{NOTAS}

1 Freud descreve os momentos da descoberta desse conceito analisando o comportamento do neto: "Enquanto procedia assim [jogando longe todo seu Spielzeug], emitia com uma expressão de interesse e de satisfação um longo e ruidoso 'o-o-ó, que segundo o julgamento concordante da mãe e do observador [da filha e do pai, da mãe e do avô aqui conjugados na mesma especulação] não era uma interjeição, mas significativo 'fort' [ali, longe]. Percebi finalmente que aquilo era um jogo e que a criança utilizava todos os seus brinquedos (Spielzeug), para brincar de ir 'embora' com eles, com seu 'estar longe' (fortsein). [...] Certo dia, fiz uma observação que confirmou minha interpretação. O menino tinha um carretel de madeira (Holzspule) com um pedaço de corda (Bindfaden) amarrado em volta dele. Nunca lhe havia ocorrido puxá-lo no chão para trás de si, por exemplo, e brincar com o carretel como se fosse um carro, mas ele jogava o carretel segurando-o pelo cordão com muita destreza (Geschick) por cima da borda de sua caminha cercada por um cortinado (ou por um véu, verhängten Bettchens), de maneira que ele desaparecia por entre as cortinas, ao mesmo tempo que o menino proferia seu 'o-o-ó' significativo (Bedeutungsvolles) e, em seguida, puxava de volta o carretel seguro pelo cordão de fora da cama, e saudava seu reaparecimento com um alegre ' $D a$ '. Essa, então, era a brincadeira completa (komplete Spiel): desaparecimento e retorno (Verschwinden und Wiederkommen), da qual só conseguíamos ver geralmente o primeiro ato, que era incansavelmente repetido como um jogo, embora sem qualquer dúvida o maior prazer se ligasse ao segundo ato" (FREUD, 1920, p. 18-19)

2 Conceito articulado por Jaques Derrida (2002b), a suplementaridade desconstrói a noção de totalidade e estabelece a presença da diferença, dá uma ideia de "falta" na estrutura do original, "Tudo começa pela reprodução. Sempre já, isto é, depósitos de um sentido que nunca esteve presente, cujo presente significado é sempre reconstituído mais tarde, nachträglich, posteriormente, suplementarmente: nachträglich também significa suplementar. $\mathrm{O}$ apelo do suplemento é aqui originário e escava aquilo que se reconstitui mais tarde como presente. O suplemento, aquilo que parece acrescentar-se como um pleno a um pleno, é também aquilo que supre." (DERRIDA, 2002b, p. 200). Constitui principalmente um ato de acrescentar, mas que não significa necessariamente somar, e sim alterar. Dentro do processo retroativo do suplemento nenhum elemento re-produzido volta em sua pureza. 